\title{
COMMENTARY
}

\section{Diaphragmatic dysfunction in the intensive care unit: caught in the cross-fire between sepsis and mechanical ventilation}

\author{
Basil J Petrof
}

See related research by Supinski and Callahan, http://ccforum.com/content/17/3/R120

\begin{abstract}
Accumulating evidence indicates that diaphragmatic weakness is common and frequently severe in mechanically ventilated patients. Supinski and Callahan now report that infection is a major risk factor for diaphragmatic weakness in this patient population. Importantly, they show that patients with the greatest levels of diaphragmatic dysfunction have a much poorer prognosis in terms of more prolonged ventilation as well as higher mortality. Mechanical ventilation itself has also been found to induce diaphragmatic weakness along with cellular changes resembling those found in sepsis. Future studies should be directed at understanding the interaction between sepsis and mechanical ventilation, and to developing therapeutic approaches that target their common cellular pathways implicated in diaphragmatic weakness.
\end{abstract}

Mechanical ventilation is one of the most frequently employed interventions in the intensive care unit (ICU). Although it is a life-saving measure, much time and effort is spent in trying to wean patients from the ventilator as quickly as possible, since mechanical ventilation is also a cause of numerous complications. In a recent issue of Critical Care, Supinski and Callahan [1] report that infection is a significant risk factor for diaphragmatic weakness and failure to wean patients from mechanical ventilation. The authors employed state of the art methods (transdiaphragmatic pressure measurements during bilateral magnetic stimulation of the phrenic nerves), and found that patients with evidence of infection had less than half the diaphragmatic pressure-generating ability of

Correspondence: basil.petrof@mcgill.ca

Meakins-Christie Laboratories and Respiratory Division, McGill University Health Centre and Research Institute, Montreal, Quebec H2X 2P2, Canada uninfected patients. In addition, patients with the most severe diaphragmatic weakness had a markedly worse prognosis. This consisted not only of a more prolonged need for ventilator support, but was also reflected in substantially higher mortality. Indeed, diaphragmatic function appeared to be a better prognostic indicator than other more conventional indices of critical illness severity, such as the Sequential Organ Failure Assessment score. Interestingly, the treating physicians in the ICU dramatically underestimated (in 90\% of patients) the degree of diaphragmatic weakness present in their mechanically ventilated patients.

These findings should be an eye opener for practicing clinicians. They point to a need for greater awareness of the very high prevalence of diaphragmatic weakness in mechanically ventilated patients. The inability to successfully wean patients from mechanical ventilation has been closely linked to an unfavorably elevated level of the respiratory muscle work load/capacity ratio [2,3]. Although great emphasis is appropriately placed upon reducing the numerator in this relationship through attempts at improving respiratory system mechanics, the denominator (reflecting respiratory muscle function) is more difficult to assess and often neglected. Nevertheless, several studies have now shown that diaphragmatic weakness is common and frequently profound in mechanically ventilated patients [4-6], although the precise reasons for this are not well understood.

Based upon the fact that even uninfected patients in the study by Supinski and Callahan exhibited a large decrease (to approximately 50\% of normal values) of diaphragmatic force-generating capacity, it seems clear that a major component of the diaphragmatic weakness observed in mechanically ventilated patients must be caused by additional factors other than infection. In this regard, another recent study reported that diaphragmatic 
weakness was present on the very first day of admission to the ICU in patients requiring mechanical ventilation for a variety of conditions, including, but not limited to, sepsis [7]. The study by Supinski and Callahan did not specifically evaluate the time course for developing diaphragmatic dysfunction, either from the time of ICU admission and initiation of mechanical ventilation, or from the onset of infection. When taken together, however, the above studies strongly suggest that diaphragmatic dysfunction constitutes a distinct, common, and under-recognized form of organ failure that occurs with many types of critical illness, and especially during sepsis.

The results of these studies in ICU patients are also consistent with a large body of data from different animal models, which have consistently demonstrated impaired diaphragmatic function during sepsis [8]. There is limited information about the impact of mechanical ventilation upon sepsis-induced diaphragmatic dysfunction, but the interaction between the two appears to be complex. Although mechanical ventilation may mitigate the adverse effects of sepsis upon diaphragmatic function and oxygen demand to the muscle very early in its course [9], there are several reasons to believe that mechanical ventilation will either worsen or impede recovery from sepsisinduced diaphragmatic dysfunction over the longer term. In this regard, mechanical ventilation itself leads to diaphragmatic atrophy and weakness in non-septic animals and humans, a phenomenon referred to as ventilatorinduced diaphragmatic dysfunction (VIDD) [10]. Furthermore, sepsis-induced diaphragmatic dysfunction and VIDD appear to share many of the same pathogenetic mechanisms, such as increased oxidative stress and mitochondrial dysfunction within diaphragm muscle fibers [11]. Therefore, the combination of sepsis and VIDD could create a 'perfect storm', with mechanical ventilation either exacerbating the magnitude of diaphragmatic weakness caused by infection or slowing the subsequent recovery of diaphragmatic function once sepsis has resolved. Further studies will be required to specifically address these questions, and there is a clear need for novel therapeutic approaches that can either reverse or limit the development of diaphragmatic weakness in mechanically ventilated patients. The presence of common cellular mechanisms implicated in sepsis-induced diaphragmatic dysfunction and VIDD raises the possibility that pharmacologic agents directed at their shared molecular targets might be effective therapies for both conditions.

\section{Abbreviations}

ICU: Intensive care unit; VIDD: Ventilator-induced diaphragmatic dysfunction.

\section{References}

1. Supinski GS, Callahan LA: Diaphragm weakness in mechanically ventilated critically ill patients. Crit Care 2013, 17:R120.

2. Tobin MJ, Laghi F, Brochard L: Role of the respiratory muscles in acute respiratory failure of COPD: lessons from weaning failure. J Appl Physiol 2009, 107:962-970.

3. Vassilakopoulos T, Zakynthinos S, Roussos C: The tension-time index and the frequency/tidal volume ratio are the major pathophysiologic determinants of weaning failure and success. Am J Respir Crit Care Med 1998, 158:378-385.

4. Watson AC, Hughes PD, Louise Harris M, Hart N, Ware RJ, Wendon J, Green M, Moxham J: Measurement of twitch transdiaphragmatic, esophageal, and endotracheal tube pressure with bilateral anterolateral magnetic phrenic nerve stimulation in patients in the intensive care unit. Crit Care Med 2001, 29:1325-1331.

5. Laghi F, Cattapan SE, Jubran A, Parthasarathy S, Warshawsky P, Choi YS, Tobin MJ: Is weaning failure caused by low-frequency fatigue of the diaphragm? Am J Respir Crit Care Med 2003, 167:120-127.

6. Hermans G, Agten A, Testelmans D, Decramer M, Gayan-Ramirez G: Increased duration of mechanical ventilation is associated with decreased diaphragmatic force: a prospective observational study. Crit Care 2010, 14:R127

7. Demoule A, Jung B, Prodanovic H, Molinari N, Chanques G, Coirault C, Matecki S, Duguet A, Similowski T, Jaber S: Diaphragm dysfunction on admission to ICU: prevalence, risk factors and prognostic impact - a prospective study. Am J Respir Crit Care Med 2013 [Epub ahead of print].

8. Callahan LA, Supinski GS: Sepsis-induced myopathy. Crit Care Med 2009, 37:S354-S367.

9. Ebihara S, Hussain SN, Danialou G, Cho WK, Gottfried SB, Petrof BJ: Mechanical ventilation protects against diaphragm injury in sepsis: interaction of oxidative and mechanical stresses. Am J Respir Crit Care Med 2002, 165:221-228.

10. Jaber $S$, Jung B, Matecki S, Petrof BJ: Clinical review: ventilator-induced diaphragmatic dysfunction - human studies confirm animal model findings! Crit Care 2011, 15:206.

11. Picard M, Jung B, Liang F, Azuelos I, Hussain S, Goldberg P, Godin R, Danialou G, Chaturvedi R, Rygiel K, Matecki S, Jaber S, Des Rosiers C, Karpati G, Ferri L, Burelle Y, Turnbull DM, Taivassalo T, Petrof BJ: Mitochondrial dysfunction and lipid accumulation in the human diaphragm during mechanical ventilation. Am J Respir Crit Care Med 2012, 186:1140-1149.

\section{$10.1186 / \mathrm{cc} 12864$}

Cite this article as: Petrof: Diaphragmatic dysfunction in the intensive care unit: caught in the cross-fire between sepsis and mechanical ventilation. Critical Care 2013, 17:R181 